\title{
INSAR TROPOSPHERIC CORRECTION COMBINING GNSS DATA AND A GLOBAL ATMOSPHERIC MODEL
}

\author{
Elisabeth Simonetto ${ }^{1}$, Frédéric Durand ${ }^{1}$, Laurent Morel ${ }^{1}$, Jean-Luc Froger ${ }^{2}$, Joëlle Nicolas ${ }^{1}$ \\ 1: GeF/L2G, ESGT, CNAM, 1 Bd Pythagore, 72000 Le Mans, France \\ elisabeth.simonetto@lecnam.net
}

2: LMV, OPGC, Université Blaise Pascal, 5 rue Kessler, 63038 Clermont-Ferrand, France

\begin{abstract}
Résumé
Les mesures issues de l'interférométrie d'images radar (InSAR), notamment satellitales, doivent être corrigées du délai dû à la propagation des ondes dans l'atmosphère. Plusieurs travaux ont déjà montré l'intérêt de cette correction. Cet article présente une méthode d'estimation de la phase troposphérique qui utilise à la fois des mesures GNSS (Global Navigation Satellite System) et un modèle d'atmosphère global (ERA-Interim). Pour évaluer cette méthode, nous comparons alors les mesures de déplacements interférométriques avant et après la correction avec les déplacements mesurés par GNSS, considérés comme référence. Les données utilisées pour les expériences sont acquises sur le Piton de la Fournaise en France.
\end{abstract}

Mots clés : InSAR, atmosphère, recalage, GNSS, correction.

\begin{abstract}
Radar interferometry measurements are mixed with the signal due to the atmosphere crossing. It has been proven the necessity to correct this signal to improve the ground deformation analysis in many contexts. This work deals with the tropospheric phase estimation using both GNSS (Global Navigation Satellite System) measurements and global atmospheric model (ERA-Interim). Then we compare the InSAR deformation measurements before and after the tropospheric phase correction with the GNSS displacement measurements, considered as reference. Experiments are performed using X-band SAR data and GNSS measurements acquired over the Piton de la Fournaise in France.
\end{abstract}

Keywords : InSAR, atmosphere, recalage, GNSS, correction.

\section{Introduction}

Radar interferometry measurements are mixed with the signal due to the atmosphere crossing (e.g., (Tarayre et Massonet, 1996 ; Zebker et al. 1997). Indeed, the crossing of the troposphere induces wave propagation delays that can be considered as stratified and turbulent delays according to the phenomena. It has been proven the necessity to correct this signal to improve the ground deformation analysis in many contexts (Jolivet et al., 2014). To mitigate the atmospheric signal in InSAR data, several methodologies have been studied by the past using one or several approaches in synergy. In (Jolivet et al., 2014), the authors distinguish two approaches : predictive and empirical. The empirical approach aims at separating the atmospheric signal from the other ones (residual orbits, residual topography, deformation) using for instance a priori model of the deformation phenomenon, adapted spatial and temporal filtering and phase-based approaches. Predictive methods use external data to evaluate the undesired signal : standard weather models, spectrometer measurements such as MERIS data, ground meteorological data or GNSS. This work proposes mitigating the tropospheric phase using GNSS measurements and a global atmospheric model (GAM).

The use of GNSS measurements for atmosphere mitigating in InSAR is discussed in several publications (Williams et al., 1998; Ge et al., 2000 ; Janssen et al., 2004 ; Onn et Zebker, 2006 ; Xu et al., 2006 ; Fornaro et al., 2015 ; Simonetto et al., 2015 ; Tang et al., 2016). In the meantime, other authors were interested to the use of GAM (see (Doin et al., 2009 ; Jolivet et al., 2014 ; Bekeart et al., 2015a; Yu et al., 2018)). These approaches provide ZHD (Zenith Hydrostatic Delay) and ZWD (Zenith Wet Delay). The ZD (Zenith Delay) is computed as the sum of these two values. The data is interpolated at the same spatial and temporal samplings as the radar images. The tropospheric phase, that denotes the phase delay due to the troposphere crossing, is derived for each date of SAR image acquisition and at each pixel using a mapping function to project the ZD into the line-of-sight of the SAR image. This leads to the Atmospheric Phase Screen (APS) that is the tropospheric phase image superimposed to the corresponding interferogram. Except in case of important high turbulences, the usefulness of mitigating the troposphere signal in InSAR with GAM was highlighted. It prevents from confusion between ground 
deformation phenomenon and long-wavelength signal due to stratified delays even for flat terrain (Jolivet et al., 2014). Furthermore, in flat areas, empirical methods based on the correlation between radar phase and topography could fail to estimate the correct relationship (Bekeart et al., 2015b). In long time series analysis, the use of GAM reduces the variance due to the seasonal effects of tropospheric delays (Doin et al., 2009 ; Jolivet et al., 2014). Temporal resolution of GAM, 4 hours per day for ERA-Interim (ECMWF) (Dee et al., 2011), or hourly for the more recent ERA5, seems convenient for our purpose. However, one can deplore the weak spatial resolution of GAM, $0.7^{\circ}$ grid for ERA-Interim and $0.36^{\circ}$ for ERA5, compared to the one of recent SAR images. The data processing from a GNSS ground receiver provides ZHD from atmosphere modelling and estimated ZWD with a quasi-continuous temporal sampling which allows the consideration of rapid atmosphere variation. As, these measurements are punctual, the authors in (Simonetto et al., 2015) propose a method to assess a height-dependent model of ZD in a global basis. In (Simonetto et al., 2015), classical interpolation methods, cubic spline or triangulation, are used to generate ZD maps. But, it is shown that the estimation is influenced by the GNSS receiver network over the study area and the interpolation method.

As consequence, we propose the troposphere mitigation combining the ZHD from a GAM, here ERA-Interim, and the ZWD from GNSS processing. Experiments are performed using X-band SAR data and GNSS measurements acquired over the Piton de la Fournaise in France. We use several software (DORIS, TRAIN, SNAPHU, GAMIT), GMT and Matlab scripts. InSAR deformation measurements before and after the correction are confronted to the GNSS displacement measurements.

\section{Proposed approach}

In this work, we focus on the analysis of single interferograms. This implies two SAR images and a DEM (Figure 1).

For each P-pixel in the SAR image, the tropospheric phase, named TP, is :

$$
\phi_{\text {tropo }}(P)=-\frac{4 \pi}{\lambda} S D(P),
$$

where $S D(P)$ is the Slant Delay at pixel P. It is obtained from the sum of the projected ZHD and ZWD into the radar line-of-sight (LOS) direction. The projection is allowed by mapping functions :

$$
S D(P)=m f_{H}(e l) Z H D(P)=m f_{w}(e l) Z W D(P),
$$

where $e l$ is the elevation angle for pixel $\mathrm{P},\left(m f_{H}, m f_{W}\right)$ are the hydrostatic and wet mapping functions.

In (Fornaro et al., 2015), it is recalled that in case of

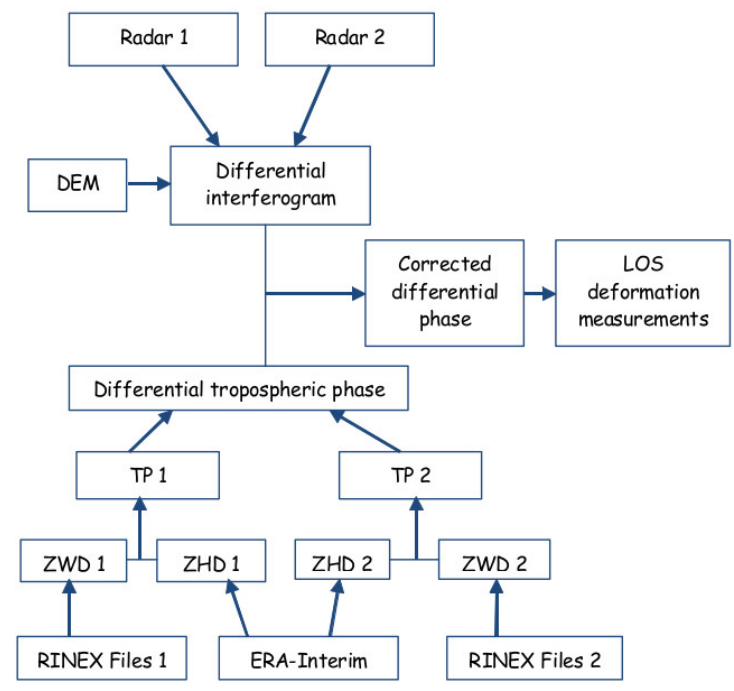

FIGURE 1 : Method flowchart.

high elevation angles and small bending effects, a first approximation is :

$$
m f_{H}(e l)=m f_{w}(e l)=\frac{1}{\sin (e l)} .
$$

So :

$$
\phi_{\text {tropo }}(P)=-\frac{4 \pi}{\lambda} \frac{Z D(P)}{\sin (e l)},
$$

Two TPs are combined to compute a differential tropospheric phase at each pixel $P$ :

$$
\Delta \Phi_{\text {tropo }}(P)=\Phi_{2, \text { tropo }}(P)-\Phi_{1, \text { tropo }}(P)
$$

This one represents the undesired contribution that is subtracted to the differential interferogram.

\section{Results}

\subsection{Study area}

We process data over the Piton de la Fournaise volcano located on La Reunion Island, France, in Indian Ocean. The volcano occupies the southeast part of the Island. It presents several cliffs open to the East. The escarpment located further East limits a large U-shaped depression open to the Indian Ocean, the Enclos Fouqué - Grandes Pentes - Grand Brûlé structure. The summit cone, located in Enclos Fouqué, rises $2630 \mathrm{~m}$. It gathers two craters : Bory and Dolomieu. This great relief is expected to produce high atmospheric artefacts in the radar interferograms. This volcano is very active with, for instance, 30 eruptive events between 2000 and 2010 (Brenguier et al., 2012). According to the arid nature of the soil over the summit part of the Enclos Fouqué - Grandes Pentes - Grand Brûlé structure, and the ground deformation amplitudes, this area is well adapted to the survey by radar interferometry. Indeed, the interferometric coherence may be high in the presence of recent lava 
flows because the vegetation is not enough developed, as shown in (Froger et al., 2012) or (Peltier et al., 2017). However, other vegetated parts of the volcano limit the use of InSAR technique.

A large radar image database exists through the CASOAR web site ${ }^{1}$ in the framework of the $\mathrm{Ol}^{2}$ (InSAR Observatory of Indian Ocean) Service of OPGC/SNOV/INSU2, in charge of the continuous InSAR monitoring of Piton de la Fournaise since 2005 (Froger et al., 2012). And, the volcano has been monitored since 1979 with permanent in situ instruments (GPS stations, seismic stations...) in the framework of the OVPF (Piton de la Fournaise Volcano Observatory) ${ }^{3}$ of IPGP. Data are made accessible through the VOLOBSIS web service ${ }^{4}$. Here, we test our approach by measuring the deformations due to the eruption of the 21st June of 2014.

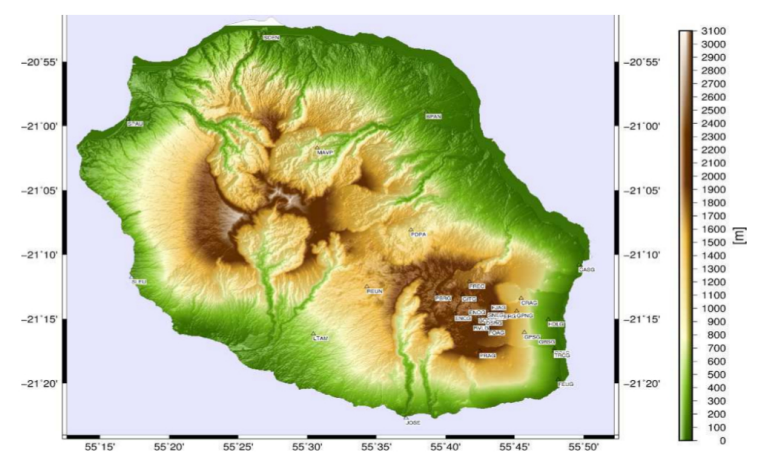

FIGURE 2 : Location of most GPS receivers used in this study around Piton de la Fournaise.

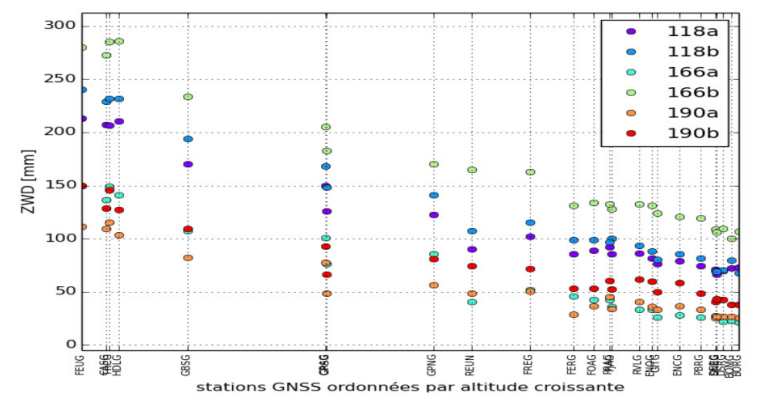

FIGURE 3 : Estimated ZWD for each GNSS station and each radar image epoch. Stations are ranked in ascending order in terms of their altitude. One colour is one date $(118,166$ or 190) and time in the day (a or b), see (Table 1).

1. https ://wwwobs.univ-bpclermont.fr/casoar/casoar_info.php, accessed in March 2015

2. http ://wwwobs.univ-bpclermont.fr/SO/televolc/volinsar/index.php, accessed in March 2015

3. http ://www.ipgp.fr/fr/ovpf/observatoire-volcanologiquepiton-de-fournaise, accessed in March 2015

4. http ://volobsis.ipgp.fr/index.php ?page=home, accessed in March 2015

\subsection{Tropospheric maps}

\section{ZWD using GNSS processing}

We utilize 23 GNSS data accessible from VOLOBSIS web site that cover the radar acquisition times and located over the Island. Besides, we also use GNSS data from RGP ${ }^{5}$ : it concerns 3 stations and 6 stations from lel@ ${ }^{6}$. The location of the GPS stations over the Island is shown on Figure 2. The GNSS RINEX files across the period are processed with the GAMIT 10.6 software (Herring et al., 2010). The data processing has two objectives : retrieving the position series and estimating the ZWD for each radar image acquisition time. According to the Figure 3 , low altitude stations reveals higher ZWD, as expected, but also higher ZWD variations. Values are ranging from around $2 \mathrm{~cm}$ to $30 \mathrm{~cm}$. The ZWD are then interpolated to the spatial sampling of the radar image using an adapted iterative procedure based on cubic spline method (see (Simonetto et al., 2015) and one of the map on Figure 4). Cross-validation for the ten stations located around the crater shows 0.1 to $8.2-\mathrm{mm}$ RMS.

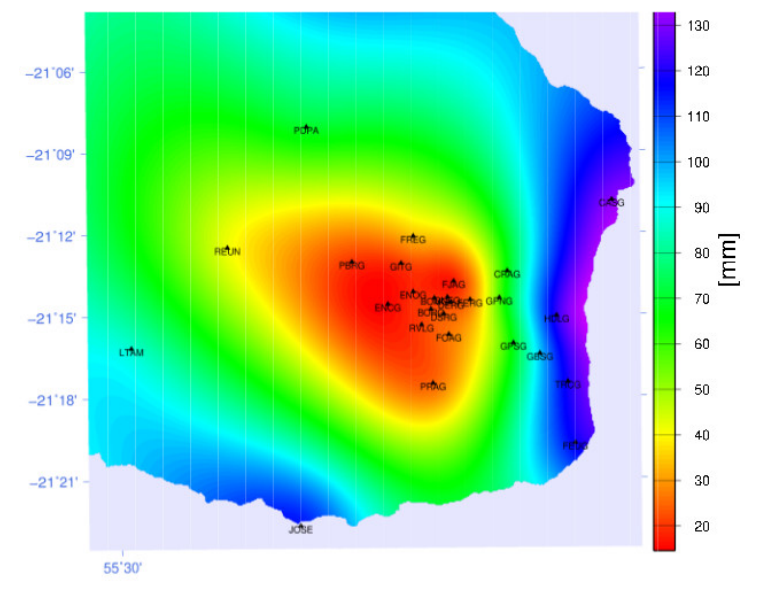

FIGURE 4 : Example of the ZWD interpolated map at $04 / 28 / 2014$ covering the ascending image.

\section{ZHD using ERA-Interim model}

For generating ZHD maps from the GAM ERAInterim, we use TRAIN (Toolbox for Reducing Atmospheric InSAR Noise) (Bekeart et al., 2015). The ERA-Interim outputs the required atmospheric parameters (pressure, temperature, relative humidity) from which ZHD and ZWD can be modelled with a $0.7^{\circ}$ spatial resolution and $6 \mathrm{~h}$ interval temporal resolution. In TRAIN, these parameters are laterally and vertically interpolated with splines. Here, we are only interested in the ZHD. These ZHD are linearly interpolated in time to fit with the radar acquisition time. One of the obtained ZHD map is displayed on Figure 5. where values are ranging from around $130 \mathrm{~cm}$ to $200 \mathrm{~cm}$.

5. http ://rgp.ign.fr, accessed in March 2015

6. http ://www.reseau-lela.com/, accessed in March 2015 


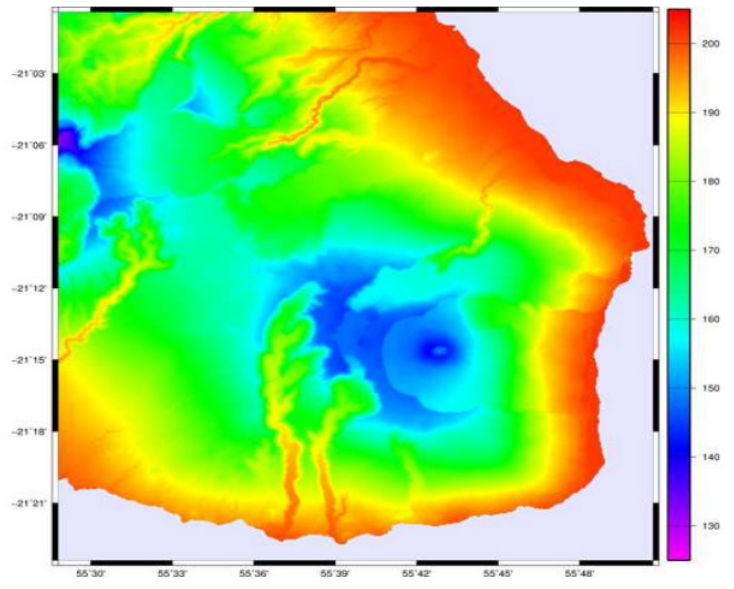

FIGURE 5 : Example of the ZHD interpolated map at $04 / 28 / 2014$ (values in $\mathrm{cm}$ ) covering the ascending image.

\subsection{INSAR LOS displacements maps}

\section{Insar data}

We use four images from COSMO-SkyMed constellation, whose dates frame the eruption that occurred on June, 21 2014. The images were acquired during the warm and wet season and the cold and dry season. These data are HImage acquired in ascending or descending pass with VV polarization mode and an incidence angle of around $35^{\circ}$. The radar wavelength is $3.1 \mathrm{~cm}$ (X-Band). Ascending and descending data is acquired at two different times of the day. For our analysis, we define four pairs (Table 1 ).
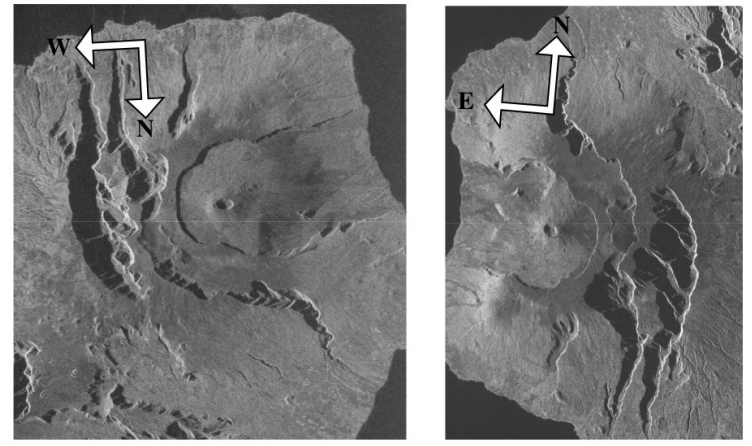

FIGURE 6 : Radar amplitude images for the 04/28/2014 ASC and DESC CSK data in radar geometry.

Standard InSAR processing is performed using the DORIS 4.06beta2 software (Kampes et al., 2003) and SNAPHU 1.4.2 (Chen et al., 2002) for phase unwrapping. Topography is compensated using a LIDAR DEM with a grid mesh size of $5 \mathrm{~m}$. The Figure 6 shows two of the radar CSK images. The couple- 1 and 2 coherence images are displayed on the Figure 7. It shows a good level around the summit but is more irregular in the area named Grandes Pentes (eastern flank).

The differential phase image for the couple-1 in Figure 9. reveals two superimposed patterns of fringes : 1) a short-wavelength bilobate pattern centered on the summit cone corresponds to the displacement induced by the June 2014 eruption and 2) a larger pattern of 7-8 fringes on the eastern flank of the volcano (Grandes Pentes - Grand Brûlé area) with a decreasing phase from the eastern base of the summit cone to the sea which corresponds to around $12 \mathrm{~cm}$ of LOS displacement away from the satellite. This pattern seems correlated with the terrain. Equivalent observations are made for the other couple-3. Descending interferograms show much more turbulent. This might be due to the time of the day : in the morning for the ascending pass and during the afternoon for the descending pass.
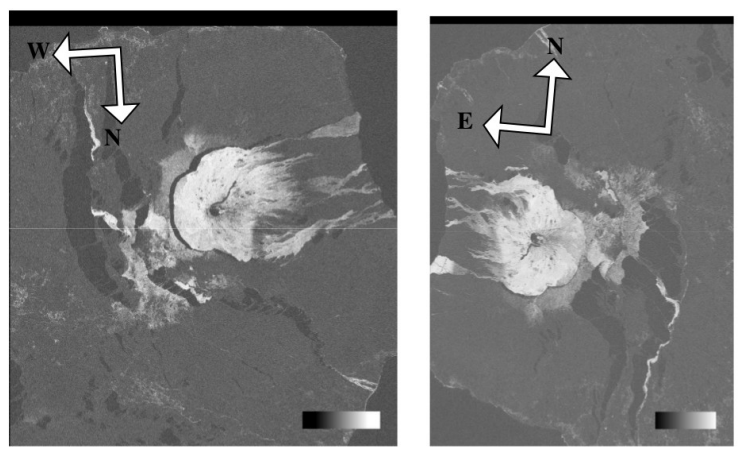

FIGURE 7 : Couple-1 and couple-2 coherence images in radar geometry (values from 0 to 1 ).

\section{Corrected interferograms}

For each image pair, the tropospheric phase computed from the previous ZHD and ZWD maps (one example on Figure 9) are subtracted from the initial interferogram. The corrected phase (Figure 10) may show less fringes especially along the height differences. Such reduction is obvious over the Grandes Pentes-Grand Brûlé, but it appears new fringes in the western part of the Enclos. This effect may be due to residual orbital errors that are not considered here or ZWD 2D interpolation errors that could occur because of the lack of GNSS stations and turbulent effects.

\section{LOS displacements analysis}

To compare GNSS and InSAR measurements, the 3D GNSS values are daily averaged and projected into the Line-Of-Sight (LOS) direction of the master radar image of each pair. The InSAR LOS displacement is extracted from interferograms using a bilinear interpolation around the exact GNSS receiver position. All values are referred to the same GNSS LOS displacement of the REUN station.

Averaged displacements measured by GNSS are presented in Table 2, in the InSAR directions. They range between $-137 \mathrm{~mm}$ and $+45 \mathrm{~mm}$. Indeed, some receivers are located on moving areas and others on stable areas. 


\begin{tabular}{|c|c|c|c|c|}
\hline Pair and Mode & Satellite - Day / time 1 & Satellite - Day / time 2 & $\mathrm{B}_{\perp}(\mathrm{m})$ & $\mathbf{B}_{\text {temp }}$ (days) \\
\hline 1 Asc & CSK S1 - 04/28/2014 (118a) & CSK S2 - 07/09/2014 (190a) & 27 & 72 \\
\hline 2 Desc & CSK S1 - 04/28/2014 (118b) & CSK S2 - 07/09/2014 (190b) & -26 & 72 \\
\hline 3 Asc & CSK S1 - 06/15/2014 (166a) & CSK S2 - 07/09/2014 (190a) & 822 & 24 \\
\hline 4 Desc & CSK S1 - 06/15/2014 (166b) & CSK S2 - 07/09/2014 (190b) & -664 & 24 \\
\hline
\end{tabular}

TABLE 1 : Radar pairs characteristics.

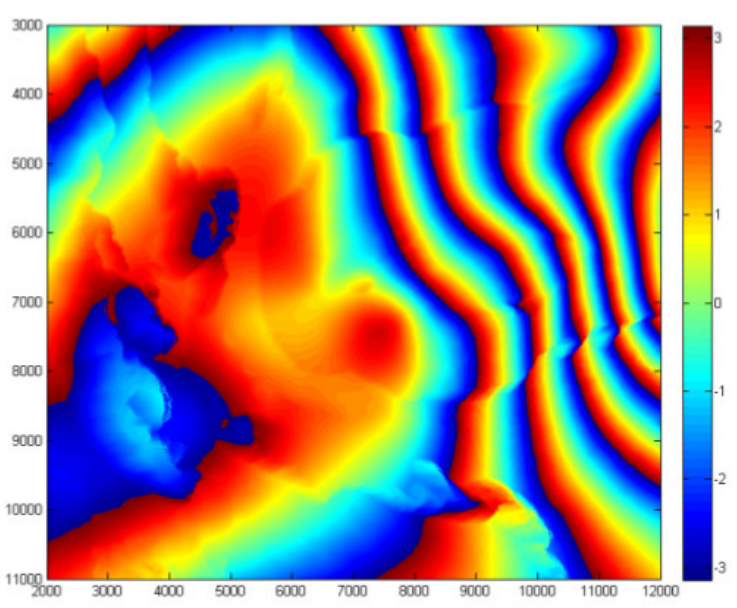

FIGURE 8 : Part of the tropospheric phase screen for the couple-1 (in radian).

\begin{tabular}{|c|c|c|c|}
\hline & \multicolumn{3}{|c|}{ GNSS mean LOS displacement amplitude } \\
(Min/Max) \\
\hline & \multicolumn{3}{|c|}{ GNSS receiver location } \\
\hline $\begin{array}{c}\text { Pair } \\
\text { Index }\end{array}$ & $\mathrm{A}$ & $\mathrm{C}$ & $\mathrm{G}$ \\
\hline $\mathbf{1}$ & $-15(-137 / 11)$ & $-23(-137 / 11)$ & $-20(-38 /-7)$ \\
\hline $\mathbf{2}$ & $-9(-95 / 45)$ & $-8(-95 / 45)$ & $-19(-33 /-8)$ \\
\hline $\mathbf{3}$ & $-13(-135 / 13)$ & $-20(-135 / 13)$ & $-20(-33 /-6)$ \\
\hline $\mathbf{4}$ & $-6(-92 / 50)$ & $-5(-92 / 50)$ & $-17(-35 /-8)$ \\
\hline
\end{tabular}

TABLE 2 : Averaged displacement values measured by GNSS and projected in the insar LOS direction in $\mathrm{mm}$ for 26 stations inside the cropped area (column A), 10 stations located around the craters (column $\mathrm{C}$ ), and 6 stations located in Grandes Pentes - Grand-Brûlé (column G).

The differences between the measured InSAR LOS displacements (without and with the tropospheric signal correction) and the displacements assessed through the GNSS processing vary from $-198 \mathrm{~mm}$ to $+393 \mathrm{~mm}$. The highest values are observed for the stations located near the costs. Around the craters and in Grandes Pentes, these differences range between $-140 \mathrm{~mm}$ and $+154 \mathrm{~mm}$. This means that the corrected terms have the same order of magnitude as those of the phenomena.

We present then the root mean square errors (RMSE) between the measured InSAR LOS displacements (without and with the tropospheric signal correction) and the displacements assessed through the GNSS processing (Table 3). As TRAIN allows to com-

\begin{tabular}{|c|c|c|c|c|c|c|c|c|c|}
\hline & \multicolumn{2}{|c|}{$\begin{array}{l}\text { GNSS recei- } \\
\text { ver location }\end{array}$} & \multicolumn{2}{l|}{$\begin{array}{l}\text { Correction } \\
\text { using only } \\
\text { ERA-Interim }\end{array}$} & \multicolumn{3}{l|}{$\begin{array}{l}\text { Correction } \\
\text { using GNSS } \\
\text { and } \\
\text { Interim } \\
\text { ERA- }\end{array}$} \\
\hline & \multicolumn{10}{|c|}{} \\
\hline $\begin{array}{c}\text { Pair } \\
\text { Index }\end{array}$ & A & C & G & A & C & G & A & C & G \\
\hline $\mathbf{1}$ & 46 & 38 & 60 & 39 & 39 & 45 & 27 & 41 & 14 \\
\hline $\mathbf{2}$ & 87 & 51 & 44 & 90 & 51 & 23 & 96 & 52 & 32 \\
\hline $\mathbf{3}$ & 72 & 67 & 61 & 71 & 62 & 64 & 67 & 85 & 46 \\
\hline $\mathbf{4}$ & 66 & 41 & 41 & 68 & 42 & 35 & 73 & 39 & 23 \\
\hline & & & & & & & \\
\end{tabular}

TABLE 3 : RMSE of InSAR LOS displacements confronted to the GNSS LOS displacements in $\mathrm{mm}$ for 26 stations inside the cropped area (column A), 10 stations located around the craters (column C), and 6 stations located in Grandes Pentes - GrandBrûlé (column G).

pute ZHD and ZWD ERA-Interim interpolated maps, we also compare our combined GNSS-GAM-based with the only GAM-based approach.

From Table 3, our approach shows good improvements of the RMSE values in the Grandes Pentes area and better results than using only ERA-Interim model. The conclusions are different around the craters where the relief variations are less important, whereas the GNSS network is denser. We think that atmosphere turbulent effects cannot explain these unexpected RMSE and that it can result from the DEM and the ZWD interpolation method. Indeed, for the DEM acquisition in 2010, many eruptive phenomena changed significantly the relief.

\section{Conclusions and perspectives}

This work has proposed the mitigation of tropospheric signal in interferograms using GAM for ZHD retrieval and GNSS measurements for ZWD assessment. This work confirms the usefulness of the atmospheric signal mitigation in InSAR and encourages further analyses on the use of the estimated GNSS atmospheric parameters. In the future, concluding remarks will be possible when studying more dates, other data (such as TSX and S1) and focusing both between eruption events and around different events. Besides, our approach does not consider important turbulences that could occur around the volcano. The effect of residual orbital errors and DEM errors should also be considered to lead to more reliable recommendations. Then the recent ERA5 GAM would be introduced in our processing chain. 

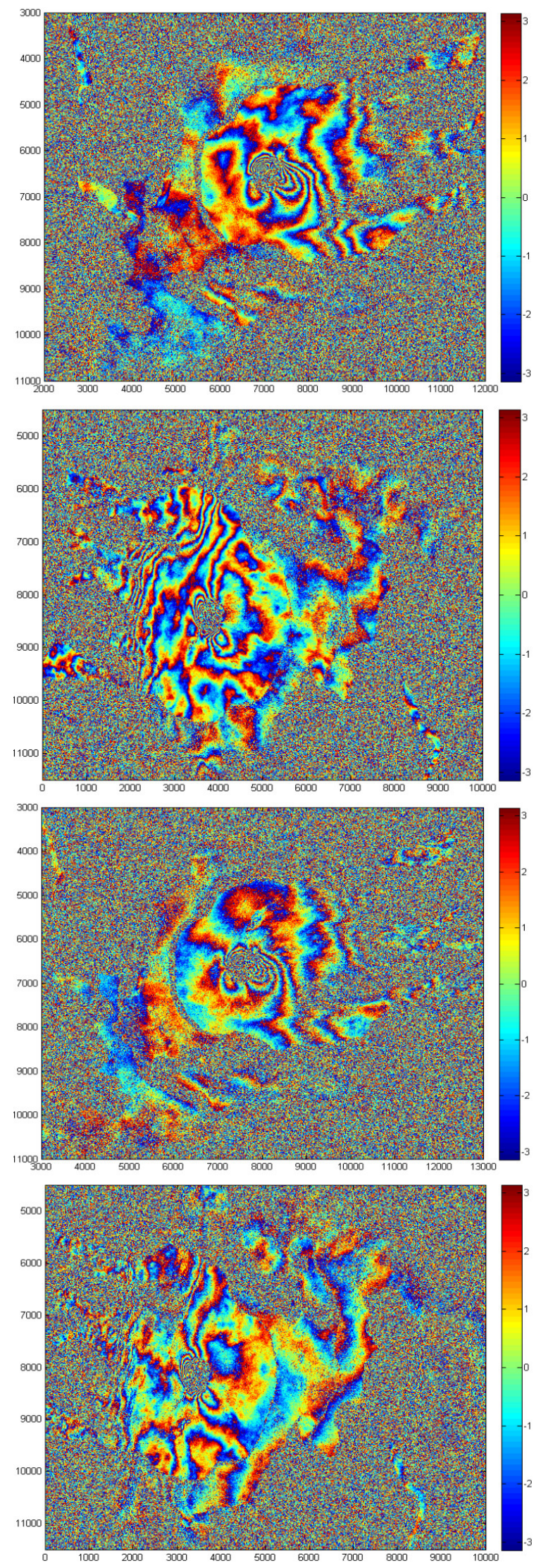

FIGURE 9 : Part of Couple-1, $-2,-3$ and -4 differential interferograms (phase in radian).
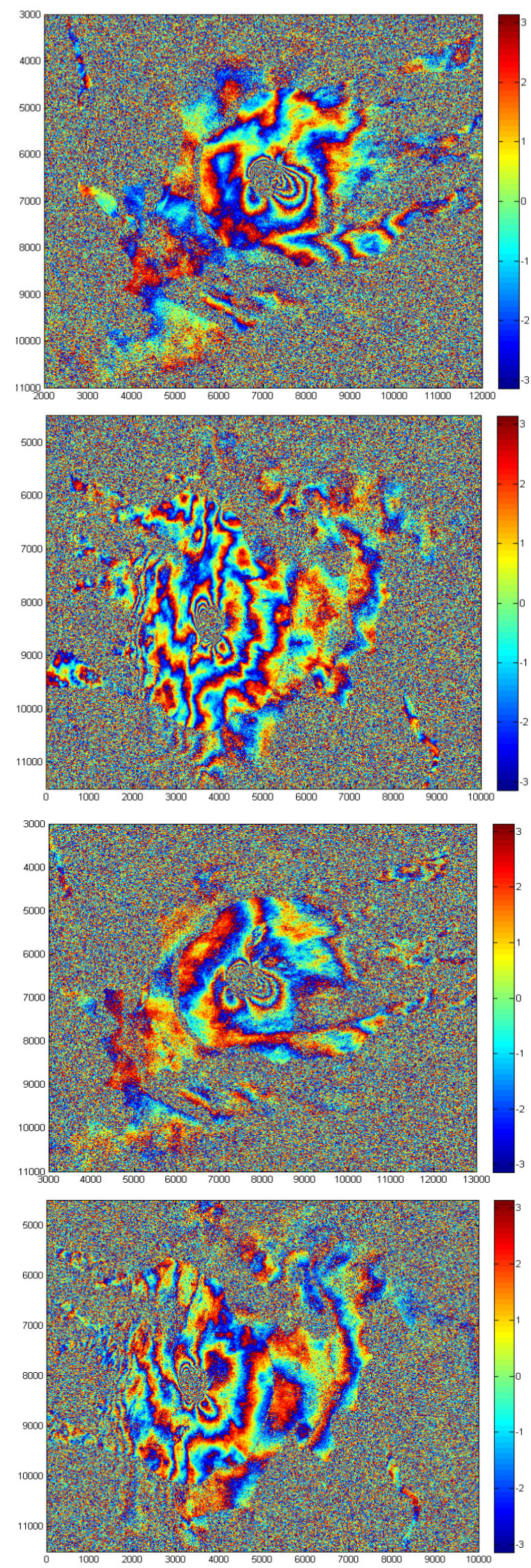

FIGURE 10 : Part of Couple-1, $-2,-3$ and 4 corrected differential interferograms (in radian). 


\section{Acknowledgements}

This work is partially funded by the French Space Agency CNES in the framework of the APR 2016 and 2017 programs.

We are grateful to all data and products providers without which this study wouldn't have been possible (IGS, IGN, IPGP with the Volobsis site, OI2/OPGC/SNOV/INSU). This research is also supported by RESIF "Réseau Sismologique et géodésique français") and by public funds from INSU in the framework of National Service for Volcanological Observations and from ANR in the framework of GEOSUD, a project (ANR- 10-EQPX-20) of the program "Investissement d'Avenir" managed by the French National Research Agency.

\section{Références}

Bekeart, D.P.S., Hooper, A., Wright, T.J. (2015). A spatially variable power law tropospheric correction technique for InSAR data. Journal of Geophysical Research Solid Earth 120(2), 1345-1356.

Bekeart, D.P.S., Walters, R.J., Wright, T.J., Hooper, A.J., Parker, D.J. (2015). Statistical comparison of InsAR tropospheric correction techniques. Remote Sensing of Environment 170, 40-47.

Brenguier, F., et al. (2012). First Results from the UnderVolc High Resolution Seismic and GPS Network Deployed on Piton de la Fournaise Volcano. Seismological Research Letters 83(1), 97-102.

Chen, C.W., Zebker, H.A. (2002). Phase unwrapping for large SAR interferograms : Statistical segmentation and generalized network models. IEEE Transactions on Geoscience and Remote Sensing, 40, 1709-1719.

Dee, D.P., et al. (2011). The ERA-Interim reanalysis : configuration and performance of the data assimilation system. Quarterly Journal of the Royal Meteorological Society 137(656), 553-597.

Doin, M.-P., Lasserre, C., Peltzer, G., Cavalié, C., Doubre, C. (2009). Corrections of stratified tropospheric delays in SAR interferometry : validation with global atmospheric models. Journal of Applied Geophysics 69(1), 35-50.

Fornaro, G., D'Agostino, N., Giuliani, R., Noviello, C., Reale, D., Verde, S. (2015). Assimilation of GPS-derived atmospheric propagation delay in DInSAR data processing. IEEE Journal on Selected Topics in Earth Observation and Remote Sensing 8(2), 874-799.

Froger, J.-L., Souriot, T., Villeneuve, N., Rabaute, T., Durand, P., Cayol, V., Di Muro, A., Staudacher, T., Fruneau, B. (2012). Apport des données Terrasar-X pour le suivi de l'activité du Piton de la Fournaise. Revue Française de Photogrammétrie et Télédétection 197, 86-101.

Ge, L., Han, S., Rizos, C. (2000). The double interpolation and double prediction (DIDP) approach for INSAR and GPS integration. The International Archives of the Photogrammetry, Remote Sensing and Spatial Information Sciences, vol.XXXIII (Part 2), 205-212.
Herring, T.A., King, R.W., McKlusky, S.C. (2010). Reference manual for the GAMIT GPS software, release, 10.3. Department of Earth, Atmospheric, and Planetary Sciences, Massachusetts Institute of Technology, Boston, USA.

Janssen, V., Ge, L., Rizos, C. (2004). Tropospheric correction to SAR interferometry from GPS observations, GPS Solutions 8, 140-151.

Jolivet, R., Agram, P. S., Lin, N. Y., Simons, M., Doin, M.P., Peltzer, G., Li, Z. (2014). Improving InSAR geodesy using Global Atmospheric Models. Journal of Geophysical Research Solid Earth 119, 2324-2341.

Kampes, B.M., Perski, Z. (2003). Radar interferometry with public domain tools. In FRINGE03, Frascati, Italy, 28 November - 2 December.

Onn, F., Zebker, H. (2006). Correction for interferometric synthetic aperture radar atmospheric phase artifacts using time series of zenith wet delay observations from a GPS network. Journal of Geophysical Research Solid Earth 111(B9).

Peltier, A., Froger, J.-L., Villeneuve, N., Catry, T. (2017). Assessing the reliability and consistency of InSAR and GNSS data for retrieving 3D-displacement rapid changes, the example of the 2015 Piton de la Fournaise eruptions. Journal of Volcanology and Geothermal Research 344, 106-120.

Simonetto, E., Durand, F., Morel, L., Froger, J.-L., Nicolas, J., Durand, S., Polidori, L. (2015). Influence of GNSS configuration and map interpolation method on InSAR atmospheric phase assessment. In FRINGE 2015, Frascati, Italy, 23-27 March.

Tang, W., Liao, M., Yuan, P. (2016). Atmospheric correction in time-series SAR interferometry for land surface deformation mapping - A case study of Taiyuan China. Advances in Space Research 58(3), 310-325.

Tarayre, H., Massonnet, D. (1996). Atmospheric propagation heterogeneities revealed by ERS-1 interferometry. Geophysical Research Letters 23(9), 989-992.

Williams, S., Bock, Y., Fang P. (1998). Integrated satellite interferometry : Tropospheric noise, GPS estimates and implications for interferometric synthetic aperture radar products. Journal of Geophysical Research 103(B11), 27051-27067.

Xu, C., Wang, H., Ge, L., Yonezawa, C., Cheng, P. (2006). InSAR tropospheric delay mitigation by GPS observations : A case study in Tokyo area. Journal of Atmospheric and Solar-Terrestrial Physics 68, 629-638.

Yu, C., Li, Z., Penna, N.T. (2018). Interferometric synthetic aperture radar atmospheric correction using a GPSbased iterative tropospheric decomposition model. Remote Sensing of Environment 204, 109-121.

Zebker, H., Rosen, P.A., Hensley, S. (1997). Atmospheric effects in interferometric synthetic aperture radar surface deformation and topographic maps. Journal of Geophysical Research 102(B4), 7547-7563. 